Okajimas Fol. anat. jap., $48: 237-270,1971$

\title{
The Glioarchitectonics of the Chicken Brain
}

\section{Astrocytes, Oligodendroglia and Other Neuroglial Cells}

By

\section{Yoshiro Inoue, Shoji Nakagawa, Yoshihiro Sugihara and Kazuyo Shimai}

\author{
Department of Anatomy, School of Medicine, Keio University \\ Shinanomachi, Shinjuku-ku, Tokyo, Japan
}

-Received for publication, August 9, 1971-

In the morphological investigation on glial cells we should first begin with metal impregnation methods because the glial cells were originally identified and classified by Golgi's (1873), Cajal's (1913 a, b) and Rio-Hortega's (1919) methods. Therefore, it is natural that there have been many arguments over the identification and cell structures of the glial cells in recent electron microscopic, autoradiographic and histochemical studies, since there is no continuity between metal impregnated images and findings by electron microscopy or nuclear stainings.

The authors have investigated the morphology and architecture of the adult chicken glial cells by various metal impregnation and nuclear staining methods under a light microscope, and at present the authors are to describe astrocytes, oligodendroglia, ependymal cells and so on, i. e. the group of so-called "neuroglia" (Polak 1965), following the preceding reports on the glial cells in the chicken optic tract (Inoue 1970) and microglia in the chicken brain (Inoue 1971).

\section{Materials and Methods}

The female chicken, weighing 1.8 to $2.0 \mathrm{~kg}$, was used in every case. The chicken brain was stained with the following methods, which were described in detail in previous papers (Inoue 1970, 1971).

1. Fixation

a) Susa-Heidenhain fixation by perfusion and immersion (Cammermeyer $1960 \mathrm{~b}$ ) 1966)

b) Bouin fixation by perfusion and immersion (Cammermeyer 
c) Carnoy, $10 \%$ formalin and Zenker fixation by immersion

The tissue blocks $2 \mathrm{~mm}$ thick were embedded in paraffin and sectioned 5 to $10 \mu$ in thickness. The whole brain fixed with $10 \%$ formalin was embedded in celloidin and cut into $40 \mu$ thick serial sections.

2. Nuclear staining

a) Mayer's hematoxylin-eosin (or PAS) staining

b) Nissl staining

Buffered thionin staining

Gallocyanin-PAS staining

Acetic thionin staining

c) Heidenhain iron hematoxylin staining

d) Chromalum hematoxylin-phloxine staining

e) Methyl green-pyronine staining

In addition, for the cyto- and myeloarchitecture of the brain, serial celloidin sections were stained with Yashiro's and WeigertPal's myelin sheath stainings and with the Nissl method.

3. Metal impregnation methods

a) Golgi method

Rio-Hortega's modification (Rio-Hortega 1928)

Ramón-Moliner's modification (Ramón-Moliner 1957)

Colonnier's modification (Colonnier 1961)

Stensaas and Stensaas' modification (Stensaas and Stensaas 1968 a)

b) Frozen section method

Ammoniacal silver methods

Rio-Hortega's method for astrocyte (Rio-Hortega 1917)

Scharenberg's method (Scharenberg 1960)

Tsujiyama's methods for astrocytes and oligodendroglia (Tsujiyama 1963)

Cajal's gold-sublimate method (Cajal 1913 a, b)

Belfry's gold chloride staining (Belfry 1968)

c) Naoumenko-Feigin method (Naoumenko and Feigin 1963)

Paraffin sections fixed with Bouin or Cajal's formalin-ammonium bromide solution were stained with ammoniacal silver carbonate solution, followed by counterstaining with Harris hematoxylin or luxol fast blue.

\section{Observation and Discussion}

Metal impregnation methods, which have been used chiefly for the morphological investigation of glial cells in light microscopy, are classified roughly into three types; first, Golgi methods in which 
tissue blocks around 2 to $3 \mathrm{~mm}$ thick are directly silver-impregnated; second, the frozen section methods in which ammoniacal silver solution or gold-sublimate solution is used; and the last, in which the paraffin and celloidin sections are used for metal stainings.

Of the three methods, the Golgi method was most likely to show the external configuration of glial cells (Polak 1965, Stensaas and Stensaas $1968 \mathrm{~b}$ ), whereas ammoniacal silver staining of frozen and embedded materials was convenient to investigate the relationship between glial cells and other constituents. Thus, in the present work the external images of glial cells will be first noted according to observations of materials stained with the Golgi method.

\section{Astrocytes}

Astrocytes in the chicken brain were classified typically into protoplasmic and fibrous astrocytes, as has been described for the mammalian brain (Kölliker 1893, Andriezen 1893, Retzius 1893, 1894, Penfield 1932 a, b, Cajal 1952, Polak 1965) and the avian brain (Eurich 1897, Stensaas and Stensaas 1968 b). Mammalian protoplasmic astrocytes stained with Golgi methods are characterized by frequent arborization of the processes and the spine-like lamellate small projections covering over the surface of the processes.

Typical protoplasmic astrocytes in the chicken telencephalon were found in the neostriatum and hyperstriatum where myelinated nerve fibers were very scarce (Fig. 1, 2 and 3). The soma of this type was round or oval and 8 to $10 \mu$ long in diameter with relatively scanty cytoplasm in perikaryon. In general up to ten or more primary processes radiated in all directions. On occasion, however, primary processes extended only from one pole of the soma (Fig. 2 and 3 ), and two of such astrocytes were commonly contiguous side by side (Fig. 2). The processes were very tortuous and arborized three to four times over their entire course with numerous small branches. The entire length of astrocytes was some 50 to $70 \mu$. The surfaces of processes were covered with roughly granular projections and showed a remarkably rugged appearance (Fig. 1, 2 and 3). Most protoplasmic astrocytes had one or more glial processes with a suckerlike foot terminating over the surface of the blood vessels. The glial feet did not differ in shape from other processes (Fig. 1).

On the other hand, fibrous astrocytes in the mammalian brain have thinner, much straighter, less numerous and lengthier processes with less arborization and the surface of their processes is smooth without any spines or lamellate projections. The typical chicken fibrous astrocytes were observed in the paleostriatum primitivum where the myelinated nerve fibers were distributed very 
densely (Fig. 4 and 5). This type had ten or so relatively smoothly extending processes which were silver-impregnated in filiform without any granular projections on their surface. The processes branched near the soma at the proximal portion of the primary processes and less frequently than those of protoplasmic astrocytes. The overall length of fibrous astrocytes was generally some 50 to $100 \mu$, but occasionally some were found in anterior commissure or other tracts whose processes extended for $200 \mu$ or so in parallel with the nerve fibers (Fig. 6). Fibrous astrocytes also possessed one or more vascular processes like protoplasmic astrocytes (Fig. 4).

Up to this time it has been pointed out that there are transitional forms between both types to varying degrees. These transitional types combine the properties of protoplasmic astrocytes with those of fibrous ones, and Stensaas and Stensaas (1968 b) defined a transitional form astrocyte as one with numerous lamellate extensions over the surface of fibrous processes. In the paleostriatum area of the chicken telencephalon the myelinated nerve fibers were distributed the densest in ventral sites, becoming gradually coarser towards the dorsal sites and resembling an open fan. In the paleostriatum augmentum near the lamina medullaris dorsalis, where the myelinated nerve fibers were rare, astrocytes were of a protoplasmic type like those in the neostriatum. However, in the paleostriatum where the myelinated nerve fibers became more numerous, astrocytes had 10 or more processes, which followed a remarkably devious course (like a protoplasmic astrocyte), branching along the entire course (like a protoplasmic astrocyte), and were covered with many granular, spine-like projections (like a protoplasmic arstrocyie). However, processes of this type were very thin and tapered away like a fibrous astrocyte (Fig. 7). Thus, these astrocytes, which were considered to have characteristics of both the two types, could be termed transitional forms. Occasionally some astrocytes were found to extend thick and fewer, fibrous processes branching a few times in their course, and were covered with numerous lamellate small projections in the tract zone like the lateral forebrain bundle (Fig. 8). This type of astrocyte corresponded closely with a transitional form which was noted by Stensaas and Stensaas (1968 b).

As the characteristic shapes of astrocytes in the chicken telencephalon have been described above, astrocytes in other parts of the brain will next be noted in some detail.

In the diencephalon, protoplasmic astrocytes were observed in the nucleus sites, and typical fibrous astrocytes in the fiber tract zone.

In the mesencephalon, the cellular zones and fibrous zones pile 
up upon one another (Kappers, Huber and Crosby 1936). In the stratum album centrale with dense myelinated nerve fibers, fibrous astrocytes extended their processes to a length of some 75 to $100 \mu$, and tended to run in a direction parallel to the nerve fibers. In gray matter layers of the stratum griseum centrale, stratum griseum paraventiculare and nucleus mesencephalicus lateralis protoplasmic astrocytes, which were closely similar in shape to those in the telencephalon, were encountered (Fig. 9). In the stratum griseum et fibrosum superficiale, some protoplasmic astrocytes extended their processes only to some 25 to $50 \mu$ in total length (Fig. 10). However, near the stratum opticum some astrocytes had somewhat fibrous processes. In the boundary region between the white matter and gray matter zones the processes of the astrocytes became more tortuous, branched more frequently and became covered with small granular projections.

In the cerebellar medulla and peduncles only fibrous astrocytes were stained with the Golgi method, extending 75 to $200 \mu$ in total length and tending to run in parallel with the myelinated nerve fibers. In the medulla part near the granule cell layer, and in the granule cell layer itself, astrocytes were somewhat different in shape from those found in other parts of the brain (Fig. 11). The perikaryon was abundant, and sent out 5 or 6 thick and fairly elongated primary processes. Secondary processes were very tortuous and branched several times. The processes were stained more or less fibrously, and tapered away.

In the molecular layer there were found Bergmann cells (Fig. 12), which are considered to be a specific form of astrocytes (Penfield $1932 \mathrm{a}, \mathrm{b})$. The Bergmann cells had their soma in the Purkinje cell layer and sent three to four primary processes towards the surface of the cerebellum nearly at right angles, branching once or twice and terminating on the pia mater. The primary processes, in general, arose from the molecular layer side of the soma, while sometimes they left the opposite side and turned the soma to extend again toward the surface. The surface of the processes was covered with small lamellate projections and showed a shaggy contour. Sometimes one or more thin and short accessory processes were found to arise from the pole facing the granule cell layer (Fig. 12). Stellate astrocytes were not observed.

In the medulla oblongata the myelinated nerve fibers ran at remarkably high density in the direction of its longitudinal axis, and between these fibers other myelinated nerve fibers ran transversely and obliquely. The groups of the nerve cells made up the nuclei between these fiber bundles. Thus, in the fiber bundles were 
found fibrous astrocytes which extended their processes with a tendency for them to be orientated in directions somewhat parallel to the nerve fibers (Fig. 14). Small, short spines further projected between the densely running nerve fibers. Astrocytes in the nuclei of the medulla oblongata resembled protoplasmic astrocytes in the telencephalon (Fig. 13). Near the boundary between the nuclei and fiber bundles astrocytes resembled a transitional form in the telencephalon, because they had fibrous processes covered with small lamellate projections like protoplasmic astrocytes.

The Golgi method, which was recommended for observation of the overall configuration of astrocytes, only enabled detection of the relationship between astrocytes and other cellular constituents with great difficulty because they were stained independently each other. On the other hand, metal impregnation methods using frozen sections demonstrated blood vessels and soma of neurons or glial cells in addition to external features of some astrocytes. So these methods have the advantage in discussions of the characteristics of glia localization (Inoue 1971).

When stained with Cajal's gold-sublimate method, in the paleostriatum primitivum or other sites, where the myelinated nerve fibers were densely crowded, there were found astrocytes with 10 or so fibrous processes which extended rather directly radiating from the perikaryon and attaining 50 to $75 \mu$ in the entire length (Fig. 15). The processes were revealed as fibrous structures which penetrated the perikaryon from one process to the opposite or adjoining one. As the outline of the perikaryon was not clearly impregnated, the nucleus seemed to be surrounded by fibrous structures which made up the main part of the processes.

In the neostriatum and hyperstriatum, fine metal grains were precipitated in the perikaryon and there were a few primary processes with secondary branches, but fibrous structures penetrating the perikaryon and processes were not observed (Fig. 16).

Thus, these astrocytes in materials stained with the gold-sublimate method were considered to correspond respectively to fibrous and protoplasmic astrocytes stained with the Golgi method, though the external configuration of the astrocytes was not shown so sharply as that of those stained with the Golgi method.

Some astrocytes which seemed to correspond to a transitional form in materials stained with the Golgi method extended thin primary processes from a round soma running tortuously and branching frequently, eventually to taper (Fig. 17). However, no fibrous structures-or very few-penetrated the soma and processes as is the case with fibrous astrocytes. 
As to the localization of astrocytes, their soma occurred in perineuronal, perivascular or intermediate sites. Two soma of astrocytes were of ten arranged side by side (Fig. 15 and 16).

Astrocytes in the cerebellar granule cell layer, which were somewhat different in shape from those in other regions, were characterized by fibrous structures penetrating the perikaryon and processes by Cajal's gold-sublimate method.

By Scharenberg's method, astrocytes were nearly the same in silver-impregnated images as in those stained with Cajal's gold-sublimate method, for their soma and processes also appeared to be fibrous (Fig. 18).

Bergmann cells with processes extending vertically to the cerebellar surface were demonstrated by Tsujiyama's method. However, small lamellate processes covering the surface of the primary processes, as shown by the Golgi method, were not stained.

It has been said that the difference between protoplasmic and fibrous astrocytes depends upon the quantity of glial fibers (fibrils) in the cytoplasm (Hosokawa $1962 \mathrm{a}, \mathrm{b}$, Hosokawa and Mannen 1963, Stensaas and Stensaas $1968 \mathrm{~b}$ ). The fact that in Cajal's gold-sublimate method metal grains were chiefly precipitated on glial fibers (fibrils) was demonstrated histologically by Hosokawa (1962 a, b), with the experimental investigation of nerve crush by Sjöstrand (1966) and in electron microscopy by Mori and Leblond (1969).

Astrocytes with clearly stained glial fibers with the gold-sublimate method were encountered where myelinated nerve fibers were densely distributed and only fibrous astrocytes had been demonstrated by the Golgi method. However, the number and length of the processes was fewer and shorter than that in materials stained with the Golgi method, since only the main processes of the astrocytes were impregnated, as described by Vaughn and Pease (1967). Protoplasmic astrocytes in the gray matter region were not impregnated so clearly by Cajal's gold-sublimate method as fibrous ones because of the lack of fibrous structures in the cytoplasm, whereas in the paleostriatum augmentum, where a transitional type of astrocytes was observed by means of the Golgi method, the astrocyte contour was stained more clear-cut though cytoplasm did not show any fibrous appearance. These findings in the chicken brain seemed to demonstrate that the degree of 'fibrization' of cytoplasm gradually decreased respectively with morphological variation from fibrous to protoplasmic astrocytes, as noted in relation to mammalian astrocytes by Hosokawa (1962 a, b).

Astrocytes in the granule cell layer of the cerebellum might have properties similar to fibrous astrocytes from the viewpoint 
mentioned above, since fiber components are found throughout the perikaryon and primary processes by means of Cajal's gold-sublimate method. There has been a conflict of opinion concerning the type of astrocytes in the granule cell layer of the cerebellum; Schroeder (1929) found protoplasmic and mixed type astrocytes in human cerebellum; Glees (1955) said that fibrous astrocytes were common; and Stensaas and Stensaas (1968 b) described protoplasmic astrocytes in avian cerebellum.

Thus, for drawing a distinction between fibrous and protoplasmic astrocytes it is necessary to examine the occurrence of glial fibers by means of Cajal's gold-sublimate method or the ammoniacal silver carbonate method in addition to the external configuration as stained with the Golgi method.

Concerning the distribution of astrocytes in the chicken brain, only protoplasmic astrocytes occurred in the gray matter regions and fibrous astrocytes were found only in the white matter. Two types of transitional astrocytes seemed to appear in the sites where myelinated nerve fibers became rarer. These characteristics of astrocyte distribution were also described by Penfield (1932a, b), Glees (1955), Hosokawa (1962a, b) and Polak (1965). Fibrous astrocytes in the gray matter regions, which were often described by other investigators, were not observed in the chicken brain by the Golgi method. However, near the pia mater and around the large blood vessels, glial cells with glial fibers stained with the gold-chloride method were very common (Fig. 19) and so the existence of fibrous astrocytes is to be expected in these areas.

\section{Oligodendroglia}

Oligodendroglia in mammalian brain, including microglia, were first distinguished from astrocytes by Rio-Hortega with his silver carbonate method (1921). Rio-Hortega (1928) further classified mammalian oligodendroglia into four types by means of the Golgi method and, in particular, suggested the intimate relationship between oligodendroglia and myelin sheath from the features of the processes.

In the chicken brain the external configuration of oligodendroglia was stained in detail with the Golgi method, and showed a difference depending upon the degree of density of myelinated nerve fibers. In the gray matter where myelinated nerve fibers were rare, such as the hyperstriatum and neostriatum in the telencephalon, the diencephalon nuclei, the stratum griseum et fibrosum superficiale in the optic tectum, and so on, oligodendroglia had a nearly round cell body and most of them were small, being around 6 to $8 \mu$ across at their greatest (Fig. 20, 21, 22 and 23). Primary processes were 5 to 10 in 
number, extending either directly or tortuously in all directions from soma, and attaining $60 \mu$ at the longest. One or two of them were often thicker than others and formed a nodularly enlarged tip, from which a few, thin secondary processes emerged (Fig. 22 and 23). Secondary and tertiary processes, as a rule, branched smoothly but sometimes nearly at right angles (Figs. 20, 21, 22 and 23). The processes had several nodules in their course, most often at their bifurcation, and showed a thin, beads-like appearance (Figs. 20, 21, 22 and 23). The processes generally tapered, whereas they sometimes had a thin, roticulate-tubular terminal (Figs. 22, 23 and 26) or nodular enlargement attaching to the axon (Figs. 21 and 26).

By means of the frozen section methods, such as Tsujiyama's method or Rio-Hortega's method, oligodendroglia were silver-impregnated similarly in shape and size to those stained by the Golgi method, provided with a round or oval soma and thin, necklace-like processes, though they stained less clearly than with the Golgi method (Fig. 24). This type of oligodendrogolia was considered to correspond to Type I of Rio-Hortega's classification.

Oligodendroglia in the gray matter region of the chicken brain stained with the Naumenko-Feigin method had a round nucleus 4 to $5 \mu$ in diameter which possessed 2 or 3 coarse chromatin granules at the center and several other chromatin granules associated with the inner surface of the nuclear membrane (Fig. 25). The cell body showed a clear-cut round, oval or pear-shape by impregnation of only the surface of the soma, and its longer diameter was almost 7 to $8 \mu$ long. The processes were very poorly silver-impregnated but successfully stained processes were beads-like as seen in the materials stained with the Golgi method (Fig. 25).

In the sites where myelinated nerve fibers were distributed densely, such as the paleostriatum, lateral forebrain bundle, each tract in the diencephalon, the white matter layer of the optic tectum, the cerebellar peduncles and in the cerebellar medulla, some oligodendroglia had a round or oval cell body with 7 to $20 \mu$ diameter at the most. Thus oligodendroglia in the white matter area had a large cell body such as was never found in the gray matter regions (Figs. 27, 28 and 29). The number of primary processes ranged from a few up to seven and was thus less than that found in the gray matter layer as described above. Primary processes emerging from a small soma were generally thin and relatively numerous (five to seven in number). These primary processes extended in all directions with remarkable tortuousity, branching two or three times. The periphery of some processes was ring-shaped (Fig. 28) and some ended in a reticulatetubular structure presumably to encircle the nerve fibers (Figs. 27 
and 28). However, some processes ended freely. Though nodular enlargements occurred sometimes in the course of processes, particularly at their bifurcation, processes were, as a rule, much smoother and longer (attaining $50 \mu$ in length) than those observed in the gray matter region (Figs. 27 and 28). The cell of this type were likely to be grouped into Rio-Hortega's Type II and III according to the shape of the processes.

Some oligodendroglia sent one to three thick primary processes and this type had mostly a large soma (Fig. 29). The thick processes extended directly from the perikaryon and their distal portions seemed to coil tortuously around nerve fibers, forming a ring or reticulatetubular structure which attained a length of 60 to $70 \mu$ (Fig. 29). The processes were smooth-surfaced and rarely showed a beads-like shape as found in the gray matter region. This type of oligodendroglia with bipolarly extending tubular processes (Fig. 29) seemed to belong to Rio-Hortega's Type IV which is said to resemble Schwann cells in the peripheral nerve. Other oligodendroglia were analogeous to Type III.

Thus Type I, II, III and IV of oligodendroglia were observed in the chicken brain just as in the mammalian brain described originally by Rio-Hortega (1928), whereas Stensaas and Stensaas (1968 b) noted Type I and II of oligodendroglia but no Type III and IV of oligodendroglia in the bird brain. Four types of oligodendroglia seemed to be related with nerve fibers (or axons): Type I and II had a nodular termination in close contact with nerve fibers (or axons) (Figs. 21 and 26) or thin and short reticulate-tubular structure at their peripheral end as if to surround the nerve fibers (Figs. 23 and 26). Type III and IV had reticulate-tubular processes which were coiled at their distal portion in various degrees around the nerve fibers (Figs. 27, 28 and 29). These findings seemed to suggest a relationship between the myelination and oligodendroglia as pointed out by many former investigators (Hardesty 1905, Rio-Hortega 1928, Alpers and Haymaker 1934, Penfield 1928, $1932 \mathrm{a}, \mathrm{b}$, Stensaas and Stensaas 1968 a, De Robertis and Gerschenfeld 1961).

Though by means of the frozen-section and paraffin-section methods using ammoniacal silver solution the detail of processes were not impregnated very well, the processes with ring-shaped ends or reticular-tubular structures were sometimes observed at sites where myelinated nerve fibers were densely distributed (Fig. 31).

3. Unknown type of glial cells

In materials stained with the Golgi method a different type of glial cells from microglia, oligodendroglia and astrocytes was found 
(Figs. 32, 33, 34, 35 and 36). Cell bodies were round, oval, kidneyshaped and sometimes triangular or sickle-shaped, and the longer diameter was 6 to $10 \mu$ across. The processes were characteristically very thin and numerous, extending in all directions and branching several times so that they were observed to lie densely one upon another under a light microscope. This type of glial cells somewhat resembled microglia in the contour of the cell body and the tendency to send thick primary processes from one pole of a cell body (Fig. 33 and 35). However, no thorn-like spines, which were characteristic in microglia, were observed and processes were much more numerous than those of microglia. Processes had a rather smooth surface and were very thin compared with those of protoplasmic astrocytes. According to the manner of extension and arborization of processes, this type was different from fibrous astrocytes. In particular, this type of glial cells had a distinct difference from astrocytes in that they possessed no vascular feet. On the other hand, there were many differences in shape, number and branching manner of processes from typical oligodendroglia in the gray and white matter.

This type of glial cells was likely to be distributed in all parts of the chicken brain without any variations in their silver-impregnated image, e.g. in gray matter regions of the telencephalon (Fig. 32), diencephalon and optic tectum (Fig. 33), molecular layer of the cerebellum and also in the lateral forebrain bundle (Fig. 34), paleostriatum primitivum, stratum album centrale (Fig. 35) of the optic tectum and every portion of the medulla oblongata, where the myelinated nerve fibers occurred densely. As to their location the cell bodies were rarely found in close contact with the nerve cell body or the blood vessel wall (Fig. 36). However, with various frozensection methods none of this type of cells was stained. This type of glial cells was first noted by Ramón-Moliner (1958) in the young cat brain by means of the Golgi method. He noted that they had smooth, mossy or sea-weed processes and might be classified as an immature type of oligodendroglia. Stensaas (1968 b) also noted this type of cells in the white matter of the 7-day chick spinal cord and presumed them to be an immature fibrous astrocyte. The mossy glial cells were encountered in the adult chicken brain whereas Ramón-Moliner (1958) described that this type of cells was not found in the brain of older mammals. Thus the mossy, sea-weed-like glial cells certainly appear in the brain of the earlier stage in postnatal development but may be encountered in the central nervous system of the adult lower animal species in phylogeny, though they have not been demonstrated in the reptile, amphibia, fish and so on. 
4. Ependymal cells

Ependymal celis have been relatively easily identified because of their location at the surface of the ventricular wall, even being stained with iron hematoxylin, methylene blue and other routine methods (Studnicka 1900, Müller 1900, Agduhr 1932). The entire features of ependymal cells stained with the Golgi method were clearly drawn in Cajal's magnificent monograph on the histology of the central nervous system of various animals (Cajal 1952). According to the figures in this monograph the cell body was generally columnar and faced the ventricle and central canal directly or indirectly with a somal protrusion. From the distal portion of the cell body mostly a single, elongated process arises with scant arborization and these processes are covered with small lamellate protrusions or have a very smooth surface without such protrusions. Sometimes these long processes branch a few times. Besides the long, main processes a few, short ancillary processes are occasionally observed. Some of the main processes end in pia mater but most cannot be traced completely to the pia mater.

Ependymal cells at the lateral ventricle of the chicken brain, on the other hand, had a columnar or hemispherical cell body facing directly the ventricle or located somewhat distant from the ventricle with a short projection to its surface. From the opposite pole to the ventricle the ependymal cell sent one or two thick and very long main processes, which sometimes branched in the course of extension, attaining more than $600 \mu$ in length (Figs. 37, 39 and 40). The surface of the main processes was often covered with spine-like projections (Figs. 37, 39 and 40) and particularly at their proximal portion thin and short side-branches occurred in varying numbers (Fig. 37). In the tangential plane of the ventricular wall, thick and short ancillary lateral processes were encountered (Fig. 38). Besides the thick and long main processes there were found thin and relatively short ancillary processes, which branched to a varying degree like processes of protoplasmic astrocytes (Fig. 40), or revealed a necklace-like shape with few branches like processes of oligodendroglia (Fig. 39). Some ependymal cells had only such ancillary processes but no main processes (Fig. 40). The significance of the difference in shape of these ancillary processes was unknown, but it might. reveal various functional differences of ependymal cells around the ventricular site.

Some of both the ancillary and main processes terminated in the: vascular wall near the ventricle (Fig. 38). However, it was not considered that all of the ependymal cells were associated with the blood vessels from observation of the silver-impregnated materials. 
In the septal area (the inner wall) of the telencephalon, the main processes of ependymal cells were found to reach the pia mater to terminate there whereas in the lateral wall it was unclear whether they extended as far as the surface of the brain. In materials stained with the frozen section method only main processes were impregnated fibrously but accessory processes and spine-like projections covering the surface of main processes were not visible.

- Stensaas and Stensaas (1968 b) classified ependymal cells of the bird and turtle into three types and observed a difference in shape according to their position. According to their classification ependymal cells in the avian brain corresponded to two of the types, one of which was 'a typical ependymal cell' with a single, smooth distal process and other was 'a lamellate ependymal cell' with a long distal process covered with small lamellate extensions. The ependymal cells in the chicken lateral ventricle certainly corresponded to 'lamellate ependymal cells' described above, but short, thin accessory processes which took various shapes, lateral processes which were demonstrated in a tangential plane, and vascular processes which terminated in the vascular wall should be added to their findings. On the other hand, Polak (1965) noted that ependymal cells in the mammalian brain sent many thin processes penetrating into the nervous tissue and some were associated with the blood vessels, and when the ventricle wall was sectioned tangentially, short lateral processes were found to arise from the apical part of a cell body. Stensaas and Stensaas (1968 b) drew an analogy between ependymal cells and protoplasmic astrocytes in the occurrence of fibrils in the cytoplasm of both cell types, and presumed that ependymal cells might transform into protoplasmic astrocytes. However, in the adult chicken brain no transitional-form cells intermediate between typical astrocytes or oligodendroglia and ependymal cells were silver-impregnated, so transformation from mature ependymal cells to astrocytes or oligodeneroglia seemed to be improbable.

\section{Morphology of nuclei}

The comparative morphology of glial cell nuclei has been discussed in detail in previous papers (Inoue 1970, 1971): the glial cells in the chicken brain had many similar features to those of other animal species in size, shape and the manner of chromatin distribution (Penfield 1924, 1932 a, b, Jakob 1927, Glees 1955, Cammermeyer 1960 b, Smart and Leblond 1961, Hosokawa and Mannen 1963, Stensaas and Stensaas 1968 a, b).

The oligodendroglia nucleus was well identified by NaoumenkoFeigin methods in which oligodendroglia were counterstained with 
hematoxylin after silver-impregnation (Fig. 25). In the hyperstriatum and neostriatum where myelinated nerve fibers were scarce the nucleus was almost round and 4 to $5 \mu$ in diameter. The nuclear membrane was thick with coarse chromatin granules on its inner aspect. At the central region of the nucleus were found 2 or 3 chromatin granules with clear-cut outline and a small number of fine chromatin granules were scattered diffusely. The nuclear sap itself was rather darker. These findings were almost similar to those of oligodendroglia in the optic tract (Fig. 41). On the other hand, in the regions where myelinated nerve fibers were rich, such as the paleostriatum, nuclei were found with a tendency to have a somewhat larger diameter and lighter nuclear sap than those described above, and they precisely corresponded in shape with those in the optic tract (Fig. 42).

The astrocyte nucleus was inferred from staining with Cajal's gold-sublimate method. Though with this method inner aspects of nuclei were not very clearly observed, the nuclei were 5 to $7 \mu$ across at their greatest with round, oval or pear-like shapes, and metal grains were precipitated, corresponding to chromatin granules and being arranged into thread-like structures radiating towards the nuclear membrane. Astrocytes were frequently arranged in pairs side by side. The protoplasmic astrocyte nucleus stained with hematoxylin, which was identified from these findings of astrocytes stained with Cajal's gold-sublimate method, was 5 to $7 \mu$ long in major diameter and almost round or kidney-shaped. The nuclear membrane was relatively thick and fine chromatin granules adhered along its inner surface. Either at the center or periphery of the nucleus there was found a mass consisting of a few coarse chromatin granules with acidophilic granules or an amorphous substance surrounding around them, from which thread-like structures radiated towards the nuclear membrane. In the nucleus fine chromatin granules were sparsely distributed (Fig. 43).

Another type of glial nucleus, which was presumed to be of astrocyte nuclei from the size of the nuclei (7 to $8 \mu$ in diameter) and the amount of perikaryon, was observed (Fig. 44). The nuclei were almost round, oval and kidney-shaped, encircled by a thin nuclear membrane. One coarse chromatin granule was attached to the inner surface of the nuclear membrane and either at the center or periphery of the nucleus two or three coarse chromatin granules were associated with acidophilic granules or an amorphous substance. From the intranuclear chromatin mass thread-like structure extended towards the nuclear membrane. Since other chromatin granules rarely occurred, the nuclear sap was pale. This type of astrocyte 
nuclei was similar to those of fibrous astrocytes in the optic tract (Inoue 1970) and very commonly found around the relatively larger blood vessels.

The ependymal cell nucleus in the lateral ventricle was round, oval or triangular, and around $7 \mu$ long in major diameter with or three chromatin granules at its center surrounded by a small amount of amorphous substance. From the central mass extended fine threadlike structure to the thinner nuclear membrane. The ependymal nuclei resembled somewhat those of astrocytes (Figs. 45 and 46). In some of the preparations the nuclear division of ependymal cells was observed in the ventricular wall (Fig. 46).

\section{Glia-neuron relationship}

It has been considered that the glial cells may take part in the metabolic activity of neurons and play a major role in transportation of matter, because by electron microscopy the extracellular space is demonstrated to be too narrow to be chiefly concerned with metabolism (De Robertis and Gerschenfeld 1961, De Robertis 1965). Particularly the perineuronal satellite glial cells are important for neurons to maintain their metabolism and are emphasized as a 'glianeuron relationship' (Hydén 1962 a, b, Takano 1965, Sjöstrand 1966 a).

In the chicken brain every type of astrocytes was often observed to exist as a perineuronal satellite by means of the Golgi method (Fig. 5), Cajal's gold-sublimate method and nuclear staining (Fig. 43), as has been demonstrated in the mammalian brain at the light microscopic level by many investigators (Andriezen 1893, Cajal 1913 b, 1952, Achucarro 1915, Brownson 1956, Schlote 1959, Hosokawa and Mannen 1963, Polak 1965, King 1966, 1968). Sjöstrand (1966 a) investigated the change of glial cells in the hypoglossal nucleus after the hypoglossal nerve crush, and noted that astrocytes reacted to carry out proliferation and hypertrophy and to increase in $\mathrm{NADH}_{2}$-reductase, though oligodendroglia did not show any change. From these findings he presumed that astrocytes might be concerned with the exchange and transportation of matter during nerve regeneration.

On the other hand Hydén (1962 a) isolated a single nerve cell and its associated glial cells, followed by chemical microanalysis, and hypothesized that nerve cells and oligodendroglia maintained a correlative metabolic relationship. In the chicken brain oligodendroglia were also demonstrated as a perineuronal satellite by means of the Golgi method, the ammoniacal silver carbonate method (Fig. 24) and nuclear staining (Fig. 41), and outnumbered perineuronal astrocytes and microglia (Inoue 1971), though a detailed quantitative investigation was not carried out. 
Cammermeyer (1966) attached importance to microglia and neglected other glial elements as perineuronal satellite cells in the rabbit brain, whereas all types of glial elements in the chicken brain, except ependymal cells, were observed as perineuronal satellite cells at the light microscopic level. However, the proof of the direct contact of the plasma membrane of nerve cells with perineuronal satellite glial cells was left to a future electron microscopic investigation.

Astrocytes and oligodendroglia in the chicken brain as well as microglia, as described in a previous paper (Inoue 1971), were also associated with the dendrites of neurons in contact with their soma (Fig. 3), and processes (Figs. 2 and 3). So the glia-neuron relationship should further be specified in terms of neuronal soma-glial soma (Figs. 5, 24, 41 and 43), neuronal soma-glial processes (Fig. 2), dendrite-glial soma (Fig. 3) and dendrite-glial processes (Figs. 2, 3 and 9) combinations. The structural information concerning these correlations ought to be obligatory for analysis of neuropils in electron microscopy, as described by Peters (1970), and for embryological and developmental investigations of glioarchitectonics.

\section{Glia-blood vessel relationship}

It has been well established from light microscopic investigation of the mammalian brain that the astrocytic processes terminate in the capillary wall with a sucker-like foot or interweave with each other to constitute the glial limiting membrane around the larger blood vessels (Andriezen 1893, Achucarro 1915, Jakob 1927, Penfield 1932 a, b, Glees 1955, Bairati 1958, Hosokawa and Mannen 1963, Polak 1965, Abandia-Fenoll, Blanco and Fairen 1969), and in the chicken brain astrocytes also maintained the same relationship with the vascular system (Figs. 1, 4, 16, 17 and 19).

In the chicken brain the perivascular satellite glial cells, whose soma was in close contact with the blood vessel wall, consisted of astrocytes (Fig. 7), oligodendroglia (Fig. 31) and an unknown type of neuroglia (Fig. 36) in addition to microglia which have already been reported (Inoue 1971), as described in relation to mammalian perivascular satellite cells (Andriezen 1893, Achucarro 1915, Jakob 1927, Penfield 1924, 1932 a, b, Cajal 1952, Glees 1955, Hosokawa and Mannen 1936, Polak 1965, King 1966). Cammermeyer (1960 a, b, c, d, 1963, 1966) investigated the perivascular satellite cells of various animal species in detail, and observed that oligodendroglia were crowded in clusters in the perivascular sites, from which he presumed that oligodendroglia might be concerned with the intrinsic control of the flow of blood in the brain. On the other hand, in the chicken brain, except for the optic tract where oligodendroglia were commonly 
found in clusters or rows around the blood vessels (Inoue 1970), both oligodendroglia and astrocytes were not observed so frequently as microglia in the perivascular portions by means of nuclear staining and silver impregnation.

\section{Comparative anatomical investigation}

The morphological classification of mammalian glial cells could be almost completely applied to adult avian glial cells in the brain and spinal cord (Eurich 1897, Bairati 1948-49, Stensaas and Stensaas 1968 b, Inoue 1970, 1971), though Ramón-Moliner's mossy oldgodendroglia (Ramón-Moliner 1958) occurred in the adult chicken brain (Figs. $32,33,34,35$ and 36 ). In species lower than the reptile, it is said that glial cells in the brain are different in type from those in the spinal cord. The glial cells in the spinal cord of the reptile and amphibia were almost similar in shape to those of the mammalian brain (Eurich 1897, Silver 1943, Stensaas and Stensaas $1968 \mathrm{a}, \mathrm{b}$ ). Though the glial cells in the spinal cord of species lower than fish have not been investigated in detail, Eurich (1897) observed the true astrocytes and ependymal cells in the spinal cord of dog-fish by means of the Golgi method, but did not refer to oligodendroglia. King (1966) investigated the telencephalon from the viewpoint of comparative anatomy by the ammoniacal silver carbonate method and demonstrated the similarity in shape of avian astrocytes and oligodendroglia to mammalian ones, whereas in the telencephalon of the animal species lower than the reptile only ependymal type glial cells existed, as described by Eurich (1897).

From the findings and discussions it could be summarized that the glial elements in the, chicken brain revealed similar characteristics in shape and localization to those in the mammalian brain. Thus authors are considering that from the view. of glioarchitectonics a definite border line could be drawn in phylogeny between the avian brain and those of animal species lower than the reptile, and consequently suggest that the glial elements in the chicken central nervous tissue are applicable for embryologic or experimental studies in a similar manner to mammalian ones.

\section{Conclusion}

1. Astrocytes, oligodendroglia, ependymal cells and an unknown type of glial cells in the adult chicken brain were observed under a light microscope by means of various kinds of metal impregnation methods and nuclear staining methods.

2. All types of neuroglial cells except the unknown type cells 
showed similar aspects to those of mammals in shape and arrangement related with the neurons (including the cell body, dendrite and axon) and the blood vessel walls.

3. The chicken brain could be used for embryological or experimental investigations instead of mammalian ones from the viewpoint of the morphological and architectonic findings concerning the glial cells, whereas the animal species lower than the reptile are remarkably different in these points from mammalia and birds.

\section{Acknowledgement}

The authors wish to express thanks to Miss Sumiko Hashimoto for her expert technical assistance.

\section{References}

Abadia, F.F., M. Blanco and A. Fairen. A study of the glia and the fibers of the cerebral plexiform layer in the cat. Anat. Anz., 125:147-160, 1969.

Achucarro, N. De l'Evolution de la Neuroglie et Specialment de ses Relation avec l'Appareil vasculaire. Trab. Lab. Invest. Biol., 13: 169-212, 1915.

- On the evolution of the neuroglia and specially their relations to the vascular apparatus. (translator's summary). J. Nerv. Ment. Dis., 48: 333, 1918.

Agduhr, E. Chorioid plexus and ependyma. Cytology and Cellular Pathology of the Nervous System, 2 : 535-610, 1932 P. B. Hoeber, New York.

Alpers, B. J. and W. Haymakers. The participation of the neuroglia in the formation of myelin in the prenatal infantile brain. Brain, $57: 195-205,1934$.

Andriezen, W. The neuroglia elements in the human brain. Brit. M. J., 2; 227-230, 1893 a.

On a system of fibre-cells surrounding the blood-vessels of the brain of man and mammals and its physiological significance. Internat. Monatsschr. f. Anat. u. Physiol., $10: 533-540,1893$ b.

Bairati, A. Perivascular relationship of the neuroglia cells. Biology of Neuroglia, 85-98, 1958, Charles C. Thomas, Illinois.

- Osservasioni camparate sulle glioarchitettonica. Mem. Accad. sc. Ist. Bologna, $6: 3-28,1948-49$.

Belfry, A. A new gold stain for astrocytes. Canad. J. Med. Techn., 30: 156-160, 1968.

Brownson, R.H. Perineuronal satellite cells in the motor cortex of aging brains. J. Neuropath, 15: 190-195, 1956.

Cajal, S. Ramon y. Sobre un nuevo proceder de impregnacion de la neuroglia y sus resultados en los centros nerviosos del hombre y animales. Trab. del Lab. de Invest. Biol. Univ. de Madrid, 11:219-237, 1913 a (Cited from "Cytology and Cellular Pathology of Nerve System, Vol. 2, 1932" edited by Penfield, W.).

- Contribucion al conocimiento de la neuroglia del cerebro humano. Trab. del Lab. de Invest. Biol. Univ. ne Madrid, 11: 255-315, 1913 b (Cited from "Cytology and Cellular Pathology of Nerve System, Vol. 2, 1932" edited by Penfield, W.).

- Histologie du Systeme Nerveux de L'Homme et des Vertelores. Vol. 2 Maloine, Paris, 1952. 
Cammermeyer, J. The distribution of oligodendrocytes in cerebral gray and white matter of several mammals. Am. J. Anat., 107: 107-127, 1960 a.

Reappraisal of the perivascular distribution of oligodendrocytes. Am. J. Anat., $106: 197-231,1960 \mathrm{~b}$.

Is the perivascular oligodendrocyte another element controlling the blood supply to neurons? Angiology, $11: 508-517,1960 \mathrm{c}$.

Differences in shape and size of neuroglial nuclei in the spinal cord due to individual, regional and technical variations. Acta. Anat., 40: 149-177, $1960 \mathrm{~d}$.

- Similarities between oligodendrocytes and cerebellar granule cell nuclei in mammalia and aves. Am. J. Anat., 112:111-139, 1963.

Cammermeyer, J. Morphologic distinctions between oligodendrocytes and microglia cells in the rabbit cerebral cortex. Am. J. Anat., 118: 227-248, 1966.

Colonnier, M. The tangential organization of the visual cortex. J. Anat., 98: 327$344,1961$.

De Robertis, E. and H. M. Gerschenfeld. Submicroscopic morphology and function of glial celis. International Review of Neurobiology, 3:1-65, 1961.

Some new electron microscopical contributions to the biology of neuroglia. Progr. Brain Res., 15 : 1-11, 1965.

Eurich, F. Contribution to the comparative anatomy of the neuroglia. J. Anat. Physiol., 32: 688-708, 1897.

Glees, P. Neuroglia Morphology and Function. Blackwell Scientific Publication, Oxford, 1955.

Golgi, C. Sulla struttura della sostanza grigia del cervello. Gaz. med. Ital. lombardia, 6, 1873 (Cited from "Neuroglia Morphology and Function" by Glees, P. 1955).

Hardesty, I. On the occurrence of sheath cells and the nature of the axones sheaths in the central nervous system. Am. J. Anat., 4: 329-354, 1905.

Hosokawa, H. A note on the glial fiber. Okajimas Folia anat. jap., 38: 315-329, 1962 a.

- The morphology of the neuroglia. Recent Advance in Research of the Nervous System, 6: 792-802, 1962 b.

- and H. Mannen. Some aspects of the histology of neuroglia. Morphology of Neuroglia, 1-52, 1963, Igakushoin.

Hydén, H. The neuron and its glia-a biochemical and functional unit. Endeavour, $144-155,1962$ a.

and P. W. Lange. $A^{*}$ kinetic study of the neuron-glia relationship. J. Cell Biol., 13 : 233-237, 1962 b.

Inoue, $Y$. The glioarchitectonics of the chicken brain. I. The glial cells in the optic tract. Okajimas Fol. anat. jap., $47: 229-265,1970$.

The glioarchitectonics of the chicken brain. II. Microglia. Okajimas Fol. anat. jap., $48: 53-82,1971$.

Jakob, A. Normale und pathologische Anatomie und Histologie des Grosshirns. Franz Deuticke, Leipz. und Wien. 1927.

Kappers, C. U. A., G. C. Huber and E. C. Crosby. The Comparative Anatomy of the Nervous System of Vertebrates Including Man. Hafner Publishing Company, New York 1936.

King, J.S. A comparative investigation of neuroglia in representative vertebrates. J. morphol., $119: 435-465,1966$.

A light and electron microscopic study of perineuronal glial cells and processes in the rabbit neocortex. Anat. Rec., 161: 111-123, 1968.

Kölliker, A. Handbuch der Gewebelehre des Menschen. 1893.

Mori, S. and C. P. Leblond. Electron microscopic features and proliferation of astrocytes in the corpus callosum of the rat. J. Comp. Neurol., 137: 197-226, 1969.

Müller, E. Studien über Neuroglia. Arch. Micro. Anat., 55: 11-62, 1900. 
Naoumenko, J. and I. Feigin. A modification for paraffin sections of silver carbonate impregnation for microglia. Acta Neuropathol., 2: 402-406, 1963.

Penfield, W.G. Oligodendroglia and its relation to classical neuroglia. Brain, 47 : 430-452, 1924.

- A method of staining oligodendroglia and microglia (combined method). Am. J. Path., 4 : 153-157, 1928.

Neuroglia. Cytology and Cellular Pathology of the Nervous System, 2: 423-479, 1932 a, P. B. Hoeber, New York.

- Neuroglia and microglia. The interstitial tissue of the central nervous system. Special Cytology-The Form and Functions of the Cell in Health and Disease, 2 : 1445-1482, 1932 b, P. B. Hoeber, New York.

Peters, A., S. L. Palay and H. de F. Webster. The Fine Structure of the Nervous System. The Cells and their Processes. Hoeber, 1970.

Polak, M. Morphological and functional characteristics of the central and peripheral neuroglia (light microscopical observations). Progr. Brain Res:, 15: 12-34, 1965.

Ramón.Moliner, E. A chlorate-formaldehyde modification of the Golgi method. Stain Technol., 92 : 105-116, 1957.

A study on neuroglia: the problem of transitional forms. J. Comp. Neurol., $110: 157-167,1958$.

Retzius, G. Studien über Ependym und Neuroglia. Biologische Untersuchungen, 5 : 9-26, 1893.

- Die Neuroglia des Gehirns beim Menschen und bei Säugethieren. Biologische Untersuchungen, 6: 1-28, 1894.

Rio-Hortega, del P. Noticia de un neuvo y facil método para la coloración de la neuroglia y del tejido conjunctivo. Trab. d. Lab. Invest. Biol. d. 1. Univ. d. Madrid, 15: 367-378, 1918 (Cited from 'McClung's Handbook of Microscopical Technique', Hafner, New York 1967).

Rio-Hortega, P. del El'tercer elemento' de los centros nerviosos. 1. La microglia en estado normal. 2. Intervencion de la microglia en los processos patologicos. 3. Naturaliza probable de la microglia. Bol. Soc. Esp. de Biol., 9 : 69-120, 1919.

- Histogenesis y evolucion normal; exodo y disribucion regional de la microglia. Arch. Neurobiol. (Madr.), 2: 212-255, 1921.

- Tercera aportacion al conocimiento morfologico e interpretación functional de la oligodendroglia. Mem. Real. Soc. esp. Hist. nat., 14:5-122, (1928) (Cited from Arch. Histol. (B. Aires), 6 : 132-183, 239-306, 1956').

Scharenberg, K. The silver carbonate technique for the impregnation of the astroglia. J. Neuropathol. and Exp. Neurol., 19:622-627, 1960.

Schlote, W. Zur Gliaarchitektonik der menschlichen Grosshirnrinde im Nissl-Bild. Arch. Psychiat. Nervenkr., 199: 573-595, 1959.

Schroeder, A.H. Die Gliaarkitektonik des menschlichen Kleinhirns. J. Psychol. Neur., 38 : 234-257, 1929.

Silver, M. B. Glial elements of the spinal cord of frog. J. Comp. Neurol. $77: 41-47$, 1942.

Sjöstrand, J. Studies on glial cells in the hypoglossal nucleus of the rabbit during nerve regeneration. Acta physiol. scand., 67 (suppl. 270); 2-17, 1966 a. - Morphological changes in glial cells during nerve regeneration. Acta physiol. scand., 67 (suppl. 270); 19-43, 1966 b.

Smart, I. and C. P. Leblond. Evidence for division and transformations of neuroglia cells in the mouse brain, as derived from radioautography after injection of thymidine-H ${ }^{8}$. J. comp. Neurol., 116:349-367, 1961.

Stensaas, L. J. and S.S. Stensaas. Astrocytic neuroglial cells, oligodendrocytes and microgliacytes in the spinal cord of the toad. I. Light microscopy. Z. Zellforsch., $84: 473-489,1968$ a.

and L_. Light microscopy of glial cells in turtles and birds. Z. Zell- 
forsch., $91: 315-340,1968$ b.

Studnicka, F. K. Untersuchungen über den Bau des Ependyms der nervosen Zentralorgane. Anat. Hefte, 15: 303-430, 1900.

Takano, I. Electron microscopic studies on retrograde chromatolysis in the hypoglossal nucleus and changes in the hypoglossal nerve, following its severance and ligation. Okajimas Fol. anat. jap., 40 : 1-69, 1964-65.

Tsujiyama, Y. Normal and pathological figures of neuroglia stained with Tsujiyama's. method. Morphology of Neuroglia, 165-180, 1963, Igakushoin.

Vaughn, J. E. and E. C. Pease. Electron microscopy of classically stained astrocytes. J. Comp. Neurol., $131:$ 143-154, 1967. 


\section{Explanation of Figures}

Fig. 1. $15 \times 40$ Golgi method

Protoplasmic astrocyte in the neostriatum.

bv : blood vessel

Fig. 2. $15 \times 20$ Golgi method

Two protoplasmic astrocytes in the neostriatum.

Arrows show the soma of two astrocytes which are contiguous side by side.

Some processes terminate in the surface of the neuronal soma (n) and the dendrite.

Fig. 3. $15 \times 100$ Golgi method

Protoplasmic astrocyte in the neostriatum.

The soma (s) and the processes (arrows) are in close contact with the dendrite (de).

Fig. 4. $15 \times 20$ Golgi method

Fibrous astrocytes in the paleostriatum primitivum.

Fig. 5. $15 \times 40$ Golgi method

Fibrous astrocyte in the paleostriatum primitivum.

The soma ( $s$ ) of astrocyte is arranged in close contact with the neuronal soma (n).

Fig. 6. $15 \times 20$ Golgi method

Fibrous astrocyte in the anterior commissure.

Fig. 7. $15 \times 40$ Golgi method

Transitional-shaped astrocytes in the paleostriatum augmentum.

The soma are both in the perivascular portion.

bv : blood vessel

Fig. 8. $15 \times 20$ Golgi method

Transitional-shaped astrocyte in the lateral forebrain bundle.

Fig. 9. $15 \times 40$ Golgi method

Protoplasmic astrocyte in the nucleus mesencephalicus lateralis.

The glial processes are associated intimately with the dendrite (de).

Fig. 10. $15 \times 40$ Golgi method

Protoplasmic astrocyte in the stratum griseum et fibrosum superficiale of the optic tectum

Fig. 11. $15 \times 40$ Golgi method

Astrocyte in the granule cell layer of the cerebellum.

Fig. 12. $15 \times 20$ Golgi method

Bergmann cell $(\mathrm{Bc})$ in the molecular layer of the cerebellum.

An arrow shows an accessory process of Bergmann cell.

Pc: Purkinje cell

$\mathrm{m}$ : microglia

Fig. 13. $15 \times 40$ Golgi method

Protoplasmic astrocyte in the medulla oblongata.

Fig. 14. $15 \times 20$ Golgi method

Fibrous astrocyte in the medulla oblongata.

Fig. 15. $15 \times 20$ Cajal's gold-sublimate method

Fibrous astrocytes in the paleostriatum primitivum.

Fig. 16. $15 \times 40$ Cajal's gold-sublimate method

Protoplasmic astrocytes in the neostriatum.

bv : blood vessel

Fig. 17. $15 \times 40$ Cajal's gold-sublimate method

Transitional-shaped astrocyte (s) in the paleostriatum augmentum.

bv : blood vessel 
Fig. 18. $15 \times 40$ Scharenberg's method

Fibrous astrocytes in the paleostriatum primitivum.

Fig. 19. $15 \times 20$ Belfry's gold-chloride method

Fibrous structures in the processes and soma of astrocytes are densely distributed in the subpial area of the cerebrum.

bv : blood vessel

Fig. 20. $15 \times 40$ Golgi method

Oligodendroglia in the neostriatum.

Fig. 21. $15 \times 40$ Golgi method

Two oligodendroglia in the neostriatum.

The processes are in contact with the axons by a nodular enlargement ( $a$, b, c).

de : dendrite

Fig. 22. $15 \times 40$ Golgi method

Oligodendroglia in the hyperstriatum.

The end of a process forms a reticulate tubular structure (d).

Fig. 23. $15 \times 100$ Golgi method

Higher magnified features of oligodendroglia in Fig. 22.

Fig. 24. $15 \times 40$ Rio-Hortega method

Perineuronal oligodendroglia (ol).

$\mathrm{n}$ : neuron

Fig. 25. $15 \times 100$ Naoumenko-Feigin method

The nucleus of oligodendroglia (ol) is demonstrated clearly by hematoxylin restaining after siver impregnation.

$\mathrm{n}$ : neuron

Fig. 26. Illustrations of oligodendroglia in Fig. 20 to 22.

The upper left corresponds to oligodendroglia in Fig. 20, the upper right to right one in Fig. 21, the lower right to left one in Fig. 21 and the lower left to one in Fig. 22.

Arrows from a to d correspond respectively to ones in Fig. 20 to 22, and show a nodular enlargement $(a, b$ and $c$ ) and a reticulate-tubular structure (d).

Fig. 27. $15 \times 40$ Golgi method

Oligodendroglia in the paleostriatum primitivum.

An arrow shows a reticulate-tubular structure which appears to encircle an axon.

Fig. 28. $15 \times 40$ Golgi method

Oligodendroglia in the paleostriatum primitivum.

Arrows show a ring-formed and coiled structure of the processes.

Fig. 29. $15 \times 40$ Golgi method

Bipolar oligodendroglia in the lateral forebrain bundle.

Fig. 30. Illustration of oligodendroglia in Fig. 29.

Fig. 31. $10 \times 40$ Rio-Hortega's method

Oligodendroglia in the paleostriatum augmentum.

Arrows show a ring-formed structure of the processes.

Fig. 32. $15 \times 40$ Golgi method

Unknown type glial cell in the hyperstriatum.

Fig. 33. $15 \times 40$ Golgi method

Unknown type glial cell in the stratum griseum et fibrosum superficiale.

Fig. 34. $15 \times 40$ Golgi method

Unknown type glial cell in the lateral forebrain bundle.

Fig. 35. $15 \times 40$ Golgi method

Unknown type glial cell in the stratum album centrale. 
Fig. 36. $15 \times 40$ Golgi method Unknown type glial cell which is located in close contact with the vascular wall (bv).

Fig. 37. $15 \times 40$ Golgi method Ependymal cell in the lateral ventricle.

Fig. 38. $15 \times 40$ Golgi method

Ependymal cells in the tangential plane of the lateral ventricle wall.

Arrows show accessory lateral processes which terminate in the blood vessel wall (bv).

Fig. 39. $15 \times 40$ Golgi method

Ependymal cell with oligodendroglia-like processes (arrow) in the lateral ventricle.

Fig. 40. $15 \times 40$ Golgi method

Ependymal cell without main, long processes in the lateral ventricle.

An arrow shows the processes resembling those of astrocytes.

Fig. 41. $15 \times 100$ Hematoxylin-eosin staining

The nucleus of the perineuronal oligodendroglia (ol) in the neostriatum.

n: neuronal soma

Fig. 42. $15 \times 100$. Hematoxylin-eosin staining

The nuclei of oligodendroglia (ol) and astrocyte (as) in the paleostriatum primitivum.

Fig. 43. $15 \times 100$ Hematoxylin-eosin staining

The nucleus (as) of the perineuronal astrocyte in the hyperstriatum.

$\mathrm{n}$ : neuronal soma

Fig. 44. $15 \times 100$ Hematoxylin-eosin staining

The nuclei (as) of astrocytes in the paleostriatum primitivum.

Fig. 45. $15 \times 100$ Hematoxylin-eosin staining

The nuclei of ependymal cells in the lateral ventricle wall.

ve: the lateral ventricle lumen

Fig. 46. $15 \times 100$ Hematoxylin-eosin staining

The nuclei of ependymal cells in the lateral ventricle wall.

An arrow reveals the nuclear division of ependymal cell.

ve: the lateral ventricle lumen 

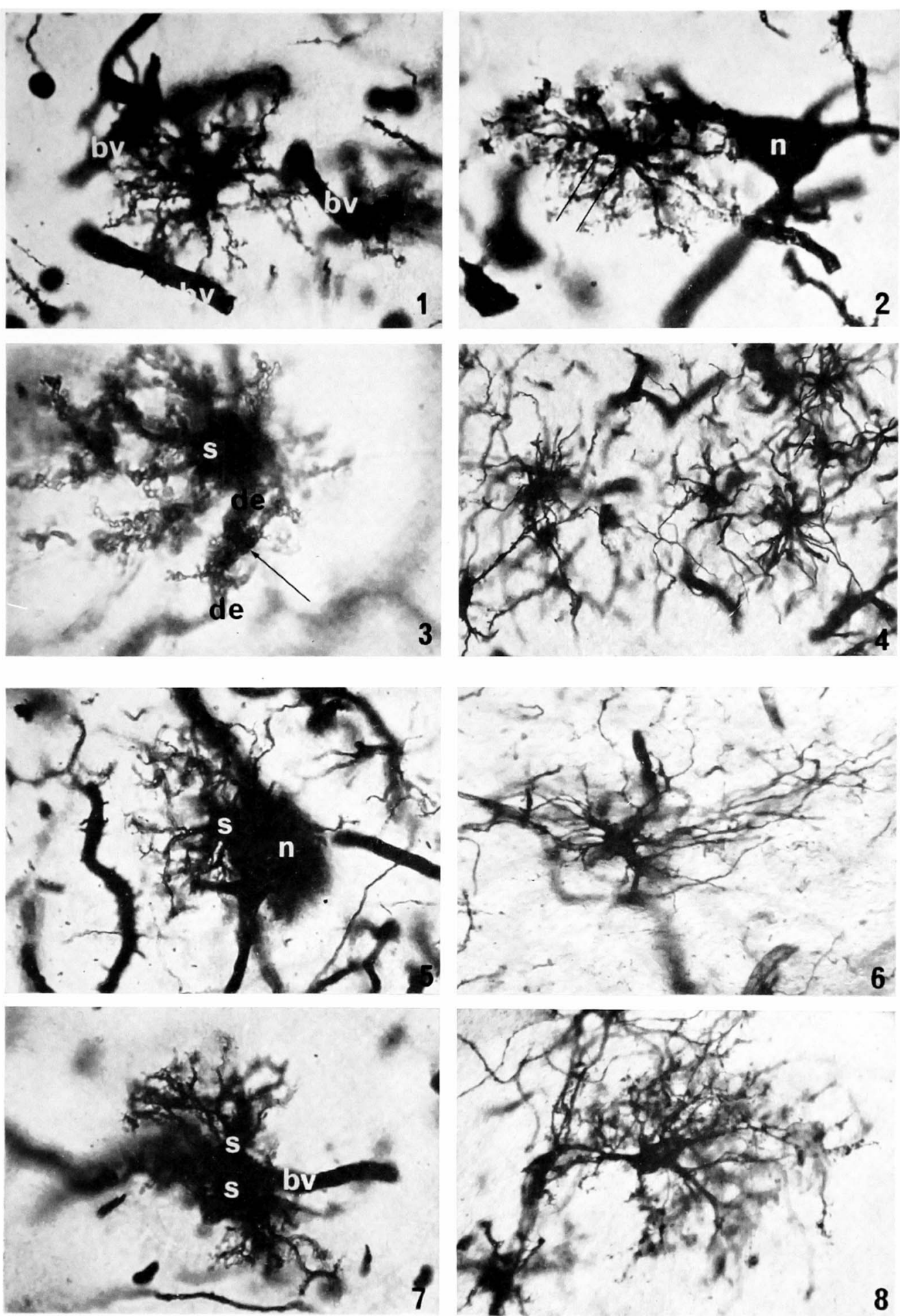

Y. Inoue, S. Nakagawa, Y. Sugihara and K. Shimai 
Plate II


Y. Inoue, S. Nakagawa, Y. Sugihara and K. Shimai 
Plate III
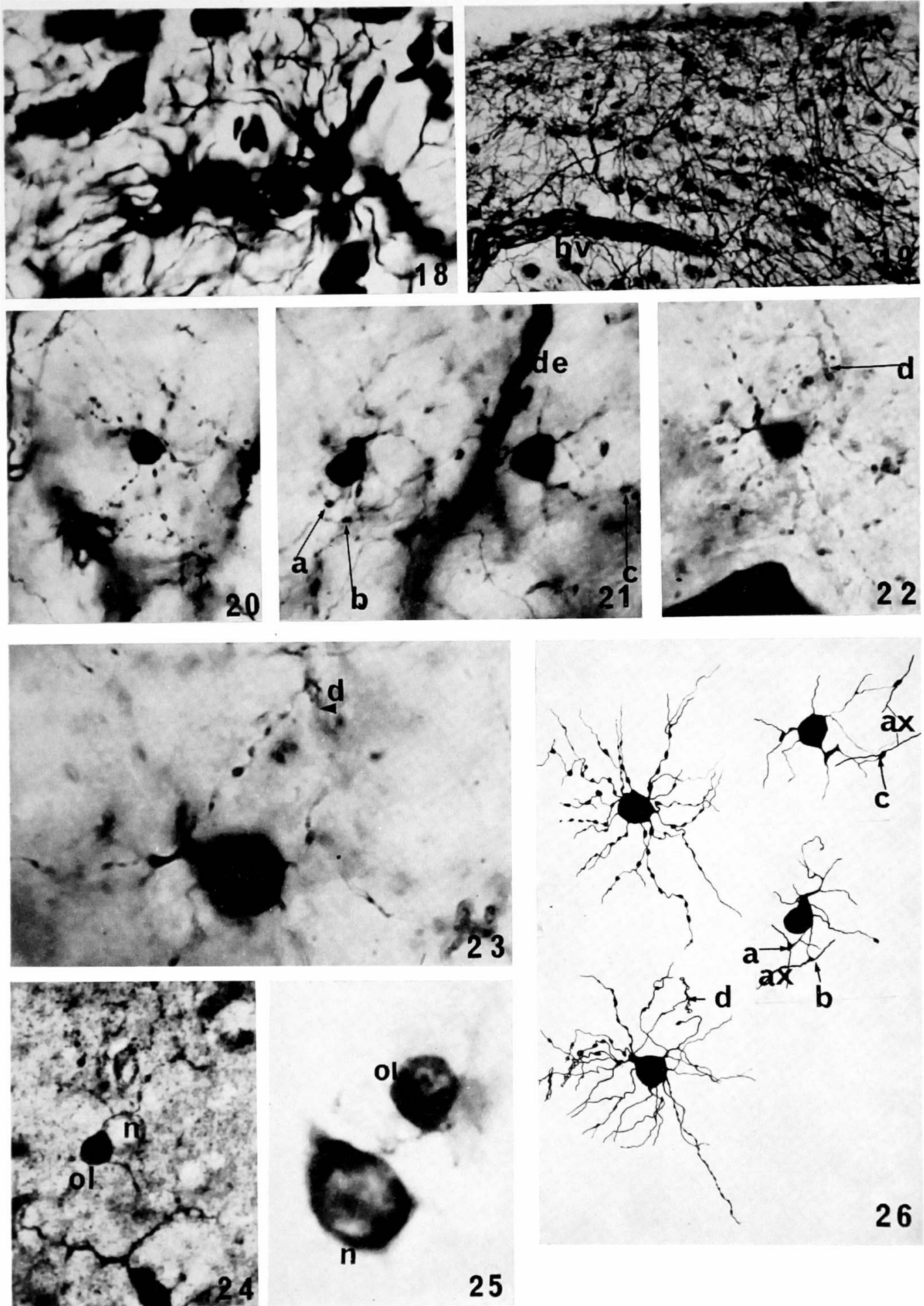

Y. Inoue, S. Nakagawa, Y. Sugihara and K. Shimai 
Plate IV
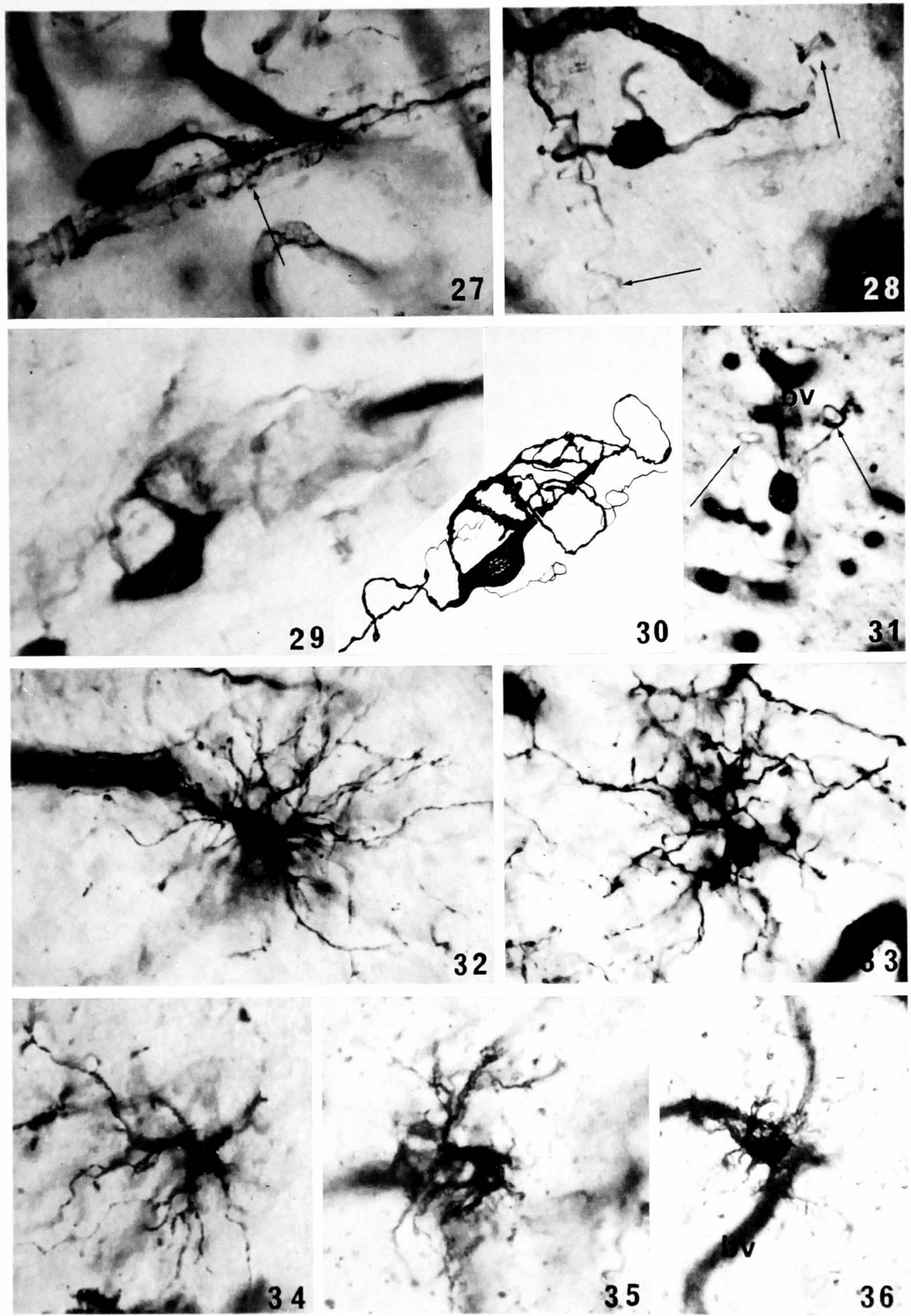

134.

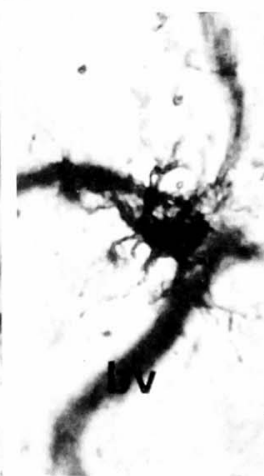

Y. Inoue, S. Nakagawa, Y. Sugihara and K. Shimai 
Plate V
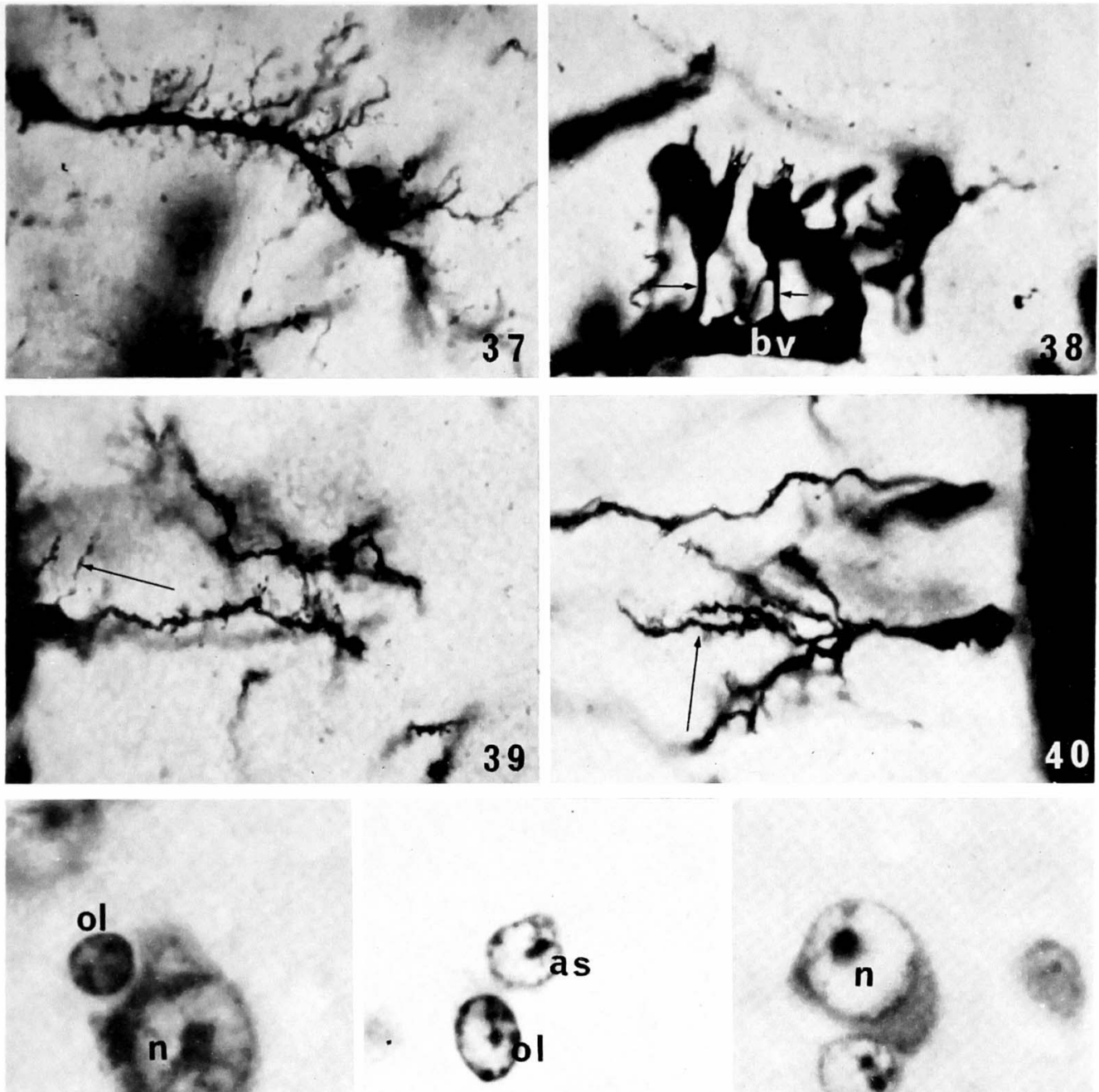

41

42


i)



Y. Inoue, S. Nakagawa, Y. Sugihara and K. Shimai 